\title{
String-driven thing
}

\section{A knotty problem.}

\section{Vaughan Stanger}

When it comes to generating energy, Robert Heinlein's maxim definitely applies: "There ain't no such thing as a free lunch." For now, the Sun continues to shine. If it stops any time soon, I guess you'll have a few hours, at most, to blame me.

Belinda and I first heard about extracting zero-point energy from the vacuum long before the news feeds got excited. Invariably the earliest of early adopters, we ordered a box of zero-point light bulbs as soon as we read the press release, despite the outrageous price. Set to hover, they made lovely Christmas ornaments.

Whoever said that perpetual motion doesn't work?

On the Twelfth day of Christmas, Belinda switched off the lowermost bulb and let it fall into her hand.

"Oh!" she yelped.

Worried that she might have scorched her hand, I swivelled in my chair.

"Did you burn yourself?"

Belinda served up her minted you're-such-a-dummy look. "Oh, Mike; you're not going senile on me, are you?" At which point I recalled that zero-point devices operate at ambient temperature.

"What's up then?"

"Not sure yet."

She was peering intently at what, from my vantage point, looked like nothing at all. First she bent down; then she stood on tiptoe; finally she crabbed around, bobbing her head, inspecting whatever it was, or wasn't, from every angle. Finally she gave a little nod accompanied by a grunt of satisfaction.

"Okay, take a look at the rug. From here." She indicated a point in mid-air with the tip of her index finger.

We really should have got rid of that fraying memento of our honeymoon years ago, but I peered at it as instructed. A small patch looked decidedly pale. Had I spilt something on it? No, evidently not, because when I raised my head the faded patch moved too.

"Oh, my!"

"Indeed," said Belinda.

I experimented some more. By looking through the designated spot from various directions I could make patches of wallpaper and curtains fade.

Now it was my turn to point at the flaw in space. "Is that where you hung the light, darling?"

"No, that's where you hung it!"

I accepted the blame with a sigh before resuming my inspection of the defect. Something had caught my eye: a tiny nub of whiteness where previously there was nothing.

"Unless I'm much mistaken," I said, "there is something here now."

With my thumbnail and forefinger pinched together, I attempted to tweeze it out. On my third attempt, I finally managed to extract a short piece of what looked remarkably like string.

"Now you've done it," Belinda said.

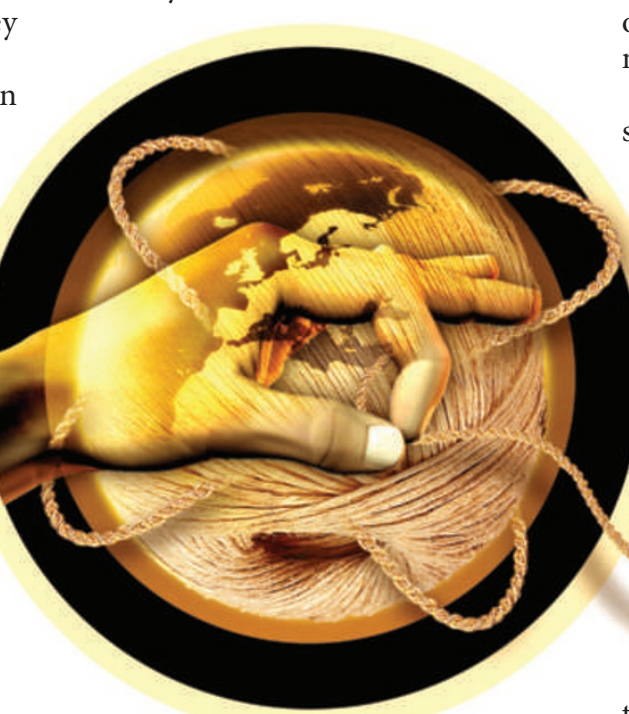

How right she was.

That evening, I fired up my laptop and sent an e-mail to BBC News. My announcement retained 'most read' status for a fortnight. I suppose someone had to be first to report the phenomenon, which is how the Jamison Effect came to be sonamed.

Before long, everyone was pulling string out of nothing. A forgotten generation of cosmologists presumably jumped for joy, albeit arthritically.

A few learned voices did express concern, but most folk continued to run their vacuum energy bulbs and other zero-point devices without batting an eyelid. As for me, well, I reverted to cranking the power handle on my laptop. Scuffing up the Universe just didn't feel right, somehow.

Now, the thing about string is that it's such a versatile material, particularly useful in these resource-limited times. Belinda, bless her, decided to knit me a string vest, but I made her wear it, because, to be frank, seeing her dressed like that did something wicked to my libido.

"Tie a knot in it, darling," she said, favouring me with a lascivious wink. I'm pretty sure she wasn't referring to the string-based necktie she'd sewn up a couple of days before, the topology of which I was still attempting to tame.

Similar scenes of blissful domesticity doubtless typified the all-too-brief era of free energy. The associated glut of string led to a cornucopia of crafts-based competitions and concerts for music played exclusively on 'stringed' instruments. Who other than me cared about the growing number of bare patches?

A killjoy physicist working for the Rus sian Academy of Sciences, that's who. Kudos to him, I say. He measured the speed of light every month for a year, achieving unprecedented accuracy. His paper in Nature caused a sensation. Further experiments revealed that the elementary charge had increased slightly. Evidently the Universe's fundamental constants weren't so constant any more. True, the changes were tiny, but that wasn't the point. The more pieces of cosmic string we pulled from thin air, the more deltas we inflicted on the fine structure constant. And as more than one eminent scientist has observed, the fundamental properties of our Universe do seem exquisitely fine-tuned for the existence of life. How many hits can $\alpha$ take before that observation no longer holds true? No one knows for sure, but I know that I never used to get this nervous before sunrise.

Only the other day, the government announced personal quotas for harvesting zero-point energy, plus a string-trading scheme. But for me, such measures don't go nearly far enough.

So, Belinda and I have bitten the bullet and declared our house a string-free zone. From now on, we'll be relying on solar power. We're the first of the un-adopters and we'll trumpet our conversion to anyone who'll listen, because the world has to learn that energy is never free.

Shortly before the publication of Vaughan Stanger's story The last botnet (Nature

Phys. 4, 744; 2008), NASA found some computer viruses on board the International Space Station. So, if you're reading this, the Universe may well be about to end. 